DOI: http://dx.doi.org/10.23925/2176-2767.2020v69p507-516

Recebido em:30/60/2020 Aprovado em: 10/08/2020

\title{
RESENHA
}

\section{RELEITURAS DA COMISSÃO RONDON: UM INVENTÁRIO DO SERTÃO BRASILEIRO}

KURY, Lorelai; SÁ, Magali Romero (org). Rondon: inventários do Brasil, 1900-1930. Rio de Janeiro: Andrea Jakobsson Estúdio, 2017. 300p.

Organizado por Lorelai Kury e Magali Romero Sá, pesquisadoras da Casa Oswaldo Cruz e especialistas em História Natural e História da Ciência no Brasil, o livro Rondon: inventários do Brasil, 1900-1930 foi capaz de apresentar uma proposta bastante original perante um tema deveras conhecido. A belíssima edição, publicada pela editora Andrea Jakobsson Estúdio, reúne uma amostra significativa do extenso e diversificado acervo dos materiais recolhidos e produzidos pela Comissão Rondon sob difíceis condições Brasil à dentro. As correspondências, relatórios, documentos iconográficos, filmes, mapas, diários, cadernetas de campo e livros, hoje localizados nos mais importantes museus e institutos culturais do Brasil, Estados Unidos e Europa, constituem importantes fragmentos da história brasileira e um rico patrimônio documental para historiadores, sociólogos, geógrafos, antropólogos, entre outros pesquisadores. A obra ainda conta,

${ }^{1}$ Graduada e mestranda em História pela Pontifícia Universidade Católica de São Paulo (PUC/SP). ORCID: 0000-0002-7559-5681 
ao final, com uma versão do texto em francês, resultado da visibilidade e do reconhecimento que os trabalhos liderados por Rondon receberam através da ampla divulgação internacional dos pioneiros registros fotográficos e fílmicos produzidos por sua equipe.

O extenso escopo de trabalhos desempenhados sob a liderança do engenheiro militar mato-grossense Cândido Mariano da Silva Rondon (1865-1958), tem recebido importante atenção da historiografia brasileira. Durante as três primeiras décadas do século XX, as incursões conhecidas como Comissão Rondon, foram responsáveis pelo reconhecimento das regiões mais remotas do território nacional. Impulsionada sob os auspícios da expansão das linhas telegráficas através da recém criada República, a Comissão, em pouco tempo, passou a incorporar uma série de incumbências políticas e científicas, cujo resultado foi a produção e divulgação de uma série de estudos e registros imagéticos acerca dessas longínquas e desconhecidas regiões. Condecorado marechal do Exército brasileiro e considerado um dos mais notáveis personagens da construção de uma nacionalidade republicana, Rondon gozou de amplo poder e influência durante toda sua vida, ainda assim, seu prestígio não encerrou uma série de capítulos contraditórios dessa trajetória "canonizada" por uma importante rede de interesses e circunstâncias próprios de sua época.

Ao reunir dez especialistas acerca dos mais diversos temas em torno da Comissão Rondon, a obra, dividida em oito capítulos, não apenas foi capaz de contemplar o diversificado escopo de suas atividades, mas procurou captar as concepções epistêmicas, bem como as questões políticas por ela ensejada, como a promoção de sentimentos "patrióticos". As diferentes contribuições procuram localizar e analisar o trabalho 
desenvolvido pela Comissão no espectro das agendas políticas do Estado brasileiro em sua recente configuração republicana. O período, marcado pelo esforço estratégico de interiorização da autoridade e do controle estatal sobre seu vasto território, pode ser reconhecido na divisa positivista Ordem e Progresso.

O tema da expansão territorial é um antigo topos da historiografia brasileira, do mesmo modo, é um velho tema da história do Brasil que remonta a sua própria condição colonial. Entretanto, foi com a proclamação da República que essa difícil tarefa foi paulatinamente alçada a mais nova e complexa etapa da vida nacional, marcada pela expansão da fronteira interna. Os trabalhos da Comissão Rondon foram responsáveis pelo início do processo de aproximação entre dois brasis, o do litoral e o do sertão, o urbano e o rural, o branco e o indígena, o letrado e o da tradição oral. Entretanto, esse período de encontros e descobertas também ficou marcado por tensões e desencontros - concretos e simbólicos.

A obra, organizada por Kury e Sá, tem como ponto de partida uma importante dimensão desse projeto expansionista: a incorporação das regiões interioranas do país enquanto lugares de memória do Brasil republicano. O primeiro capítulo - escrito pelas especialistas em pensamento intelectual no Brasil República, Nísia Trindade Lima e Dominichi Miranda de Sá -, trata dos nexos entre as incursões promovidas pelo Estado e as imagens produzidas por seus membros acerca desses territórios, seus potenciais naturais e suas populações. Isto é, como essas incursões e seus registros contribuíram no processo de construção de representações da vida no Brasil, assim como na formulação de um pensamento social e intelectual brasileiro durante aquele período. 
Ainda que a ambiciosa empreitada de integrar os remotos sertões do Oeste através da expansão do telégrafo tenha sido redimensionada pela rápida superação deste mecanismo de comunicação, os documentos produzidos por militares, civis e regionais constituem um acervo de fontes incontornável para captar o processo de construção e de interiorização do Estado nacional brasileiro durante as primeiras décadas do século XX. Os documentos produzidos ao longo dos mais de $50.000 \mathrm{~km}^{2}$ arduamente percorridos constituem o mais rico e duradouro legado da Comissão Rondon.

É nesse sentido que as autoras chamam a atenção para as possibilidades de utilização desses documentos dentro das mais diversas temáticas de pesquisa. Para além dos temas que já receberam alguma atenção da historiografia, como é o caso dos projetos político e econômico do Estado brasileiro em torno da "civilização" do sertão, as formas de ocupação do espaço, exercício da autoridade pública e a construção da identidade nacional, existem perspectivas sociológicas e antropológicas que permitem extrair desses registros questões tais quais família, alimentação, gênero, doenças, vestuário, trabalho, formas de opressão, violência e dominação.

No capítulo seguinte, Maria de Fátima Costa, pesquisadora da temática de artistas-viajantes e expedições científicas com foco no estado de Mato Grosso, aponta que os mapas, cadernetas de campo e livros produzidos pela equipe de Rondon representam um ponto decisivo de um longo processo cumulativo de saberes e estudos sobre essas regiões interioranas. Ao apresentar uma série de diálogos entre as incursões realizadas por Rondon e os adentramentos que o antecederam, a autora 
aponta que a Comissão não apenas utilizou uma série de descrições e cartografias produzidas por viajantes estrangeiros durante boa parte do século XIX, mas colocou a prova muitas das informações existentes, o que resultou na sistematização de um imenso patrimônio documental sobre a região do atual estado do Mato Grosso.

Esses registros, produzidos durante os trabalhos da Comissão Rondon, exerceram papel fundamental para fortalecer a agenda política acerca da incorporação dos territórios localizados a Oeste do país, cuja força foi crescente nas décadas seguintes, vide as políticas do governo Vargas, de Juscelino Kubitschek e da ditadura militar. O interesse estratégico acerca da integração do Mato Grosso ao tecido econômico e simbólico do Brasil, seja pela sua localização fronteiriça, seja pelas riquezas naturais ou potencial agropastoril, continuaram a atrair iniciativas estatais e privadas em busca do seu aproveitamento econômico, além do interesse geoestratégico em ocupar e integrar a região à vida nacional. Não apenas os materiais produzidos, mas a forma organizativa da equipe chefiada por Rondon foi empregada em incursões durante as década seguintes, como foi o caso da Expedição Roncador-Xingu (1943-1948), ponta de lança da Marcha para o Oeste na década de 1940, projeto de integração nacional impulsionado pelo Estado Novo.

Conforme Iris Kantor, especialista em cartografia ibero-americana, o levantamento topográfico e hidrográfico empreendido pela Comissão Rondon além de constituir patrimônio documental para a história ambiental e territorial, nos permite reconstituir algumas das principais dinâmicas territoriais que modelaram a matriz espacial brasileira na Primeira República. Do mesmo modo, ela foi responsável pela retomada e pela 
fixação de antigas rotas de comunicação intracontinental ainda não claramente definidas nos mapas do período colonial e imperial através da recuperação de rastros toponímicos e relatos dos séculos anteriores. Além de um importante marco da acumulação de memórias geográficas, as incursões de Rondon marcam a transição dos adentramentos e estudos estrangeiros de corte colonial para o início dos projetos e das políticas nacionais voltados para a integração territorial e de desenvolvimento econômico.

A pesquisadora, ao se debruçar sobre os processos de reconhecimento dos rios Telles Pires e Paranatinga, notou forte impulso de nomeação de rios e acidentes geográficos ainda não devidamente assinalados na cartografia de períodos anteriores. Em locais estratégicos de comunicação fluvial, a autora nota o emprego do "método" chamado de cartografia afetiva. Isto é, Rondon procurava homenagear seus superiores e colegas que de algum modo tinham parte nas expedições Brasil à dentro. Esse foi um importante mecanismo voltado não apenas para a inclusão desses locais enquanto lugares de memória do Brasil Republicano, mas para a consolidação de sua posse e pertencimento através do registro na documentação oficial produzida e atualizada pela Comissão Rondon.

As atividades de caráter científico, incorporadas paulatinamente aos trabalhos da Comissão, tornaram-se, em pouco tempo, seu principal ofício através da parceria estabelecida com a mais antiga instituição científica brasileira, o Museu Nacional. O resultado foi a ampliação do acervo etnográfico e de história natural não apenas deste museu, que recebeu a maior parte do diversificado material recolhido e produzido, mas também 
do Museu Americano de História Natural e o Jardim Botânico de Berlim que até hoje abrigam importante parcela desses materiais.

É sobre a dimensão científica dos trabalhos desempenhados pelo interior do Brasil que Magali Romero de Sá, uma das organizadoras do livro, se debruçou. Especializada em viagens e coleções científicas séculos XIX e $\mathrm{XX}$, a pesquisadora chama a atenção para a concepção positivista de ciência da época, amplamente difundida no Museu Nacional e fervorosamente defendida por Rondon. Concebidas enquanto a chave para o progresso e para a civilização, as atribuições científicas foram incorporadas pela Comissão para aprimorar a finalidade de seus trabalhos: a expansão e ocupação do território nacional. Ainda que pautada por essa visão positivista, as atividades desenvolvidas contribuíram para impulsionar e valorizar o trabalho, de campo ou de gabinete, de cientistas e naturalistas brasileiros empenhados em ampliar o conhecimento sobre o interior do país.

Esse empreendimento - um dos mais notáveis dentro da história da ciência brasileira - foi amplamente registrado através das lentes dos mais modernos equipamentos da época. Logo após a ampliação das atividades científicas, foi criada a Seção de Cinematografia e Fotografia composta por uma série de profissionais contratados para registrar a incursão pelo sertão brasileiro. O pesquisador Fernando de Tacca, cuja tese de doutoramento é sobre a imagética da Comissão Rondon, nos apresenta um importante capítulo acerca da fotografia e cinematografia da Comissão Rondon através de seu principal fotógrafo, Luiz Thomaz Reis.

Publicadas nas páginas dos principais jornais e apresentada para os setores mais influentes do país, as imagens produzidas foram um 
importante mecanismo para assegurar a legitimação e a continuidade das atividades da Comissão. O trabalho pioneiro divulgado também no exterior, não apenas impressionou as elites urbanas, sedentas por imagens e informações sobre o sertão brasileiro e seus povos indígenas, mas também foi considerado um dos primeiros registros do cinema etnográfico.

A difusão desses registros imagéticos acerca dos encontros com uma série de povos indígenas, assim como os discursos propagados por Rondon sobre a necessidade de sua integração estratégica à sociedade enquanto defensores das fronteiras nacionais, foram responsáveis por alçar a centralidade dessa atividade ao escopo da Comissão. O trabalho desenvolvido sob a liderança de Rondon inspirou a criação, em 1910, do Serviço de Proteção aos Índios (SPI), primeiro órgão governamental laico empenhado na proteção legal dos nativos. A identificação das territorialidades indígenas e o registro sistemático e comparativo da diversidade indígena brasileira foi responsável pela construção de um riquíssimo arquivo etnográfico, tema sobre o qual a antropóloga Marta Amoroso, especialista em etnologia ameríndia, construiu seu capítulo.

O "trabalho titânico" em torno da construção de um arquivo etnográfico e o desenvolvimento de técnicas não violentas de atração, renderam à Rondon o posto de grande indigenista da Primeira República. Entretanto, paradoxalmente, as atividades desenvolvidas em meio aos povos indígenas consistem em um dos aspectos mais complexos e contraditórios de sua atuação. Ainda que Rondon tenha dado início a oposição crítica ao modelo religioso tutelar e à disputa pela secularização dos aparelhos administrativos de tutela dos povos indígenas, o método por ele desenvolvido e propagado não abandonou a catequese como 
instrumento de pedagogia civilizatória e nacionalizante. No lugar do monopólio da Igreja Católica, o positivismo - na figura de Rondon e do SPI - assumiu a hegemonia do novo ordenamento institucional tutelar, cuja proteção passou a ser exercida pelas forças militares do Estado e alinhado ao projeto de defesa das fronteiras nacionais. Mesmo com a parcial desvalorização das ideias positivistas durante as décadas seguintes, essas condutas tutelares, denominadas pela autora "catequese secular", continuaram a ser empregadas durante todo o século XX encontrando seus limites apenas nos marcos constitucionais de 1988.

Impresso ainda hoje na bandeira nacional, o positivismo é uma complexa e importante temática para se compreender não apenas a atuação de Rondon, mas a formação da própria república brasileira. E é com essa temática, cuja influência nas políticas de Estado, no setor militar, nas práticas indigenista e na produção científica e técnica do país durante as primeiras décadas da formação do Estado-nação brasileiro, que o último capítulo encerra a obra.

Escrito pela outra organizadora, Lorelai Kury, em conjunto ao filósofo francês, Laurent Fedi, a reflexão proposta é capaz de amarrar todas as temáticas e discussões anteriores. Os autores, ao desenvolver uma reflexão acerca do arsenal de argumentos científicos, filosóficos, morais e políticos em torno da atuação de Rondon, apontam o ideal de nação encarnado por suas atividades, para o qual convergiam ciência, humanismo e atuação forte das instituições públicas.

Personagem emblemático das primeiras décadas da República brasileira, Marechal Rondon e o extenso e diversificado repertório de suas atividades ainda hoje atraem a atenção de pesquisadores do Brasil e do 
exterior. Os volumosos e riquíssimos acervos documentais, principal legado da Comissão Rondon, constituem importantes inventários da história brasileira. A obra organizada por Kury e Sá tem o mérito de reunir uma amostra significativa desses fragmentos que são o testemunho do encontro, ou da colisão, de dois mundos: o das modernas técnicas de filmagem e o dos longínquos sertões brasileiros. As imagens e as temáticas trabalhadas no livro funcionam como uma excelente introdução a figura de Rondon e as suas incursões, mas também um bom levantamento de fontes para estudantes e pesquisadores.

É de se notar que na maior parte dos capítulos a mostra do imenso acervo de fontes produzidas pela Comissão Rondon, não foi contemplada por análises específicas dos materiais selecionados para compor a obra. Em alguns capítulos, mais do que outros, os documentos acabaram cumprindo uma função de teor mais ilustrativo. Ainda assim, a qualidade da edição, das fotografias e das legendas refletem o trabalho de uma obra minuciosamente pensada e voltada para instigar novos e velhos pesquisadores sobre as diversas temáticas que fazem parte dessa longa marcha Brasil à dentro. A ausência de análises voltadas para as fontes apresentadas não diminui a riqueza da obra que através do seu rico material provoca a imersão do leitor num outro tempo e espaço. 